\title{
Symposium Overview
}

\author{
William H. Greene ${ }^{1} \cdot$ Robert G. Chambers ${ }^{2} \cdot$ Victor Podinovski $^{3}$
}

Accepted: 12 April 2021 / Published online: 8 May 2021

(c) The Author(s), under exclusive licence to Springer Science+Business Media, LLC, part of Springer Nature 2021

The papers that follow represent the first of what is anticipated to be an irregular series of special-topic Symposia sponsored by the Journal of Productivity Analysis. The intent of the series is to give leading scholars in the productivity and efficiency community the chance to exchange ideas on topics that have proven both controversial and of particular interest to that community.

The first topic chosen by the editors of the Journal was the proper modeling of production systems that produce both desirable and undesirable outputs. Bob Chambers, acting on behalf of the Editorial Board, coordinated this Symposium. Finn Førsund was asked to prepare a centerpiece paper on the broad topic, and three sets of Reviewers (Rolf Färe and Shawna Grosskopf, R. Robert
Russell and Sushama Murty, and Frederic Ang and Hervé Dakpo) were asked to review Professor Førsund's paper and provide comments. Professor Førsund was then given the opportunity to revise his contribution, and the Reviewers were then asked to provide written Commentaries on the result. The process closed with Professor Førsund providing a final rejoinder to the Commentaries.

We hope that the readership enjoys and learns as much from these intellectual exchanges as we, the Editors, have.

\section{Compliance with ethical standards}

Conflict of interest The authors declare no competing interests.
This is a part of Symposium on Proper modelling of production systems that produce both desirable and undesirable outputs. This symposium has an introduction by Chambers et al. (https://doi.org/10. $1007 / \mathrm{s} 11123-021-00607-y$ ) and is associated with original publication by Førsund et al. (https://doi.org/10.1007/s11123-021-00599-9), Commentaries by Russell et al. (https://doi.org/10.1007/s11123-02100603), Dakpo et al. (https://doi.org/10.1007/s11123-021-00606-z), Grosskopf et al. (https://doi.org/10.1007/s11123-021-00604-1) and rejoinder by Førsund (https://doi.org/10.1007/s11123-021-00605-0).

\footnotetext{
Robert G. Chambers

rchamber@umd.edu

New York University, New York, NY, USA

2 University of Maryland, College Park, MD, USA

3 Loughborough University, London, UK
} 